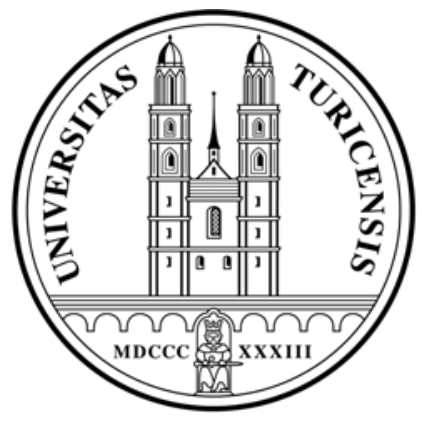

Institute for Empirical Research in Economics

University of Zurich

Working Paper Series

ISSN 1424-0459

Working Paper No. 365

Central Bank Design with Heterogeneous Agents

Aleksander Berentsen and Carlo Strub

April 2008 


\title{
Central Bank Design with Heterogeneous Agents*
}

\author{
Aleksander Berentsen ${ }^{\dagger}$ \\ Carlo Strub $\ddagger$ \\ University of Basel University of Basel
}

September 20, 2007

\begin{abstract}
We study alternative institutional arrangements for the determination of monetary policy in a general equilibrium model with heterogeneous agents, where monetary policy has redistributive effects. Inflation is determined by a policy board using either simple-majority voting, supermajority voting, or bargaining. We compare the equilibrium inflation rates to the first-best allocation.
\end{abstract}

\begin{tabular}{ll|}
\hline Keywords: & policy board, monetary policy, search \\
JEL Classification: & E4, E5, D7 \\
\hline
\end{tabular}

\footnotetext{
${ }^{*}$ The authors thank the Swiss National Science Foundation and the Swiss National Bank for financial support. We are grateful to James Bullard, Alexei Deviatov, Yvan Lengwiler, Mariana Rojas Breu, Christopher Waller, and Cédric Wasser for most valuable discussions. We also thank the seminar participants at the 2007 Money, Banking, Payments, and Finance Workshop at the Federal Reserve Bank of Cleveland. All errors are ours.

†aleksander.berentsen@unibas.ch

$\ddagger_{\text {cs@carlostrub.ch }}$
} 


\section{Introduction}

This paper studies alternative decision-making models for the determination of monetary policy. We consider a general equilibrium model with heterogeneous consumers. Differences in preferences yield diverse inflation aversions. Monetary policy is decided within a policy board that represents the agents' preferences. This allows us to compare the outcome of the following central bank designs: first, we analyze simple-majority voting and supermajority voting, i.e. majority voting with veto power for the minority. Then, we analyze a policy board, where the representatives of each group of agents bargain over the money growth rate with and without allowing for lump-sum transfers 1

Our framework builds on the representative agent model of Lagos and Wright (2005). Their model is useful because it allows us to introduce heterogeneous preferences for consumption while still keeping the distribution of money balances tracktable. Agents have either high or a low utility from consumption. The main consequence is that there is a two-point distribution of money holdings and, therefore, monetary policy has redistributive effects as the inflation tax affects agents differently 2

The following results emerge from the model. First, the social planner's desired inflation rate is the Friedman Rule, i.e. an inflation rate at the rate of time preferences. This efficient outcome is attained if, under simple-majority voting, the agents with low-inflation preferences have the majority. Under bargaining, first-best can only be attained when transfers are feasible. Second, under all other central bank designs the equilibrium outcome does not attain the first-best allocation. In particular, under some simple-majority voting, when the agents with high inflation preferences have a majority, the resulting inflation is strictly above the Friedman Rule. The same is true for bargaining and for supermajority voting.

An interesting aspect of our findings is that when we study two separate economies, one populated by agents with low preferences for consumptions and

\footnotetext{
${ }^{1}$ See Persson and Tabellini 2000 and Gerling, Grüner, Kiel, and Schulte 2003) for expositions and surveys of different decision-making mechanisms.

${ }^{2}$ Redistributive effects of monetary policy in a different context have been studied in Berentsen, Camera, and Waller 2005), Bhattacharya, Haslag, and Martin 2005), Bhattacharya, Haslag, and Russell 2005), Boel and Camera (2006), Molico (2006), or Haslag and Martin (2007).
} 
the other populated with agents with high preferences for consumptions, each prefers the Friedman Rule. In particular for any central bank design the outcome will be the Friedman Rule in each economy. If these two economies form a monetary union, then a deviation of the Friedman Rule can be the outcome. This is due to the redistributional effect of inflation in an economy with heterogeneous agents 3

Bullard and Waller (2004) have the most closely related analysis. They discuss the advantages of various alternative decision-making models in an overlapping-generations model. First, they find that if the inflation-averse agents have a minority, the resulting inflation is infinite. In contrast, under the same institutional rule, the equilibrium inflation rate in our model is above the Friedman Rule, but it is finite. This major difference is due to their use of the overlappinggenerations model where the young generation prefers a hyperinflation. Second, in their model, a constitutional rule (i.e. supermajority voting) implements the first-best allocation. In our model however, supermajority voting never yields the first-best allocation. As they remark (p. 112), "the problems with majority voting and bargaining are remedied by giving the older, minority generation a veto over proposed policy changes [using supermajority voting]. This acts as a form of commitment, causing the young to choose monetary policy based on lifetime utility, and thus to create a stationary equilibrium at the social optimum."

We propose a different solution to attain the first-best allocation: bargaining with transfers. Appropriate transfers allow the economy to move to the Friedman Rule from any status quo inflation rate since the agents who lose from the change of monetary policy are compensated. If the transfers are lump-sum, they yield a Pareto superior allocation. One interpretation of our result is that monetary policy needs to be linked to fiscal policy since this allows for such transfers.

We organize the paper as follows. In section 2 , we present the environment. Section 3 analyzes monetary equilibria and the optimality of the Friedman Rule. Section 4 then examines alternative institutional arrangements for the determination of monetary policy and discusses the results. Extending our model in section 5 allows us to interpret our results similar to those of Erosa and Ventura

${ }^{3}$ This result, although derived in a very different context, is in accordance with Hagen and Süppel 1994. 
2002). Finally, we provide a brief conclusion.

\section{The Model}

Time is discrete. There is a $[0,1]$ continuum of infinite-lived agents. In each period, two Walrasian markets open and close sequentially 4 Only one market is open at any one time. We assume there are two perishable goods produced and consumed by all agents. Agents get utility $U(x)$ from consuming $x \geq 0$ of a generalized good with $U(0)=0, U^{\prime}(x)>0, U^{\prime}(0)=\infty, U^{\prime}(+\infty)=0$, and $U^{\prime \prime}(x)<0$ in the first market. In the second market, an agent gets utility $\varepsilon u(q)$ from consuming the specialized good $q \geq 0$ where $u(0)=0, u^{\prime}(q)>0, u^{\prime}(0)=\infty, u^{\prime}(+\infty)=0$, $u^{\prime \prime}(q)<0$, and $u^{\prime \prime \prime}(q)>05$ In the first market, agents provide working hours $h$ at the linear cost function $c(h)=h$. The cost of producing a good in the second market is linear, i.e. $c(q)=q$.

There are three types of agents: sellers, labeled $s$, and two types of buyers, labeled $l$ and $h$, as explained below. Sellers produce in the second market and consume in the first market. Buyers, however, consume in the second market and produce and consume in the first. The timing is as follows: at the beginning of each period, the first market opens. Then, after settling all trades, the second market opens. Figure 1 provides a simple illustration of our model's timing.

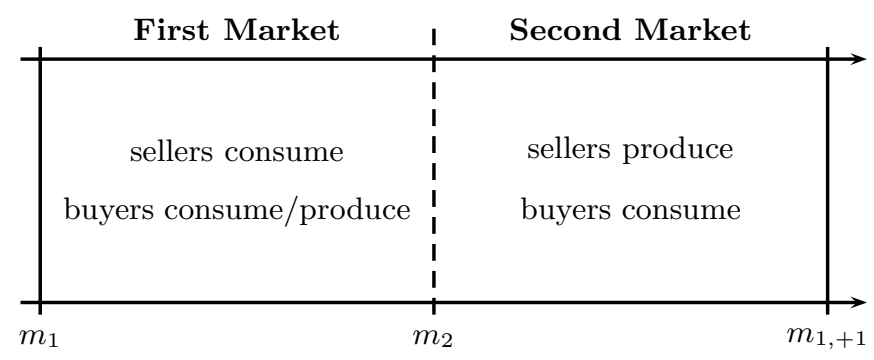

Figure 1: The Model

The two buyer types differ in their marginal utility as follows. The low type, $l$, receives utility $\varepsilon^{l} u(q)$ and the high type, $h$, utility $\varepsilon^{h} u(q)$ when they consume $q$

\footnotetext{
4By assuming competitive pricing in all markets, we depart from Lagos and Wright 2005) as for example in Rocheteau and Wright (2005).

5The CRRA utility functions, for example, satisfy these requirements.
} 
in the second market, where $0<\varepsilon^{l}<\varepsilon^{h}$. In the first market, all agents, regardless of their state, can provide labor $h$ as well as consume the homogeneous good $x$. The measures of buyers and of sellers are each normalized to 1 . The measure of low-type buyers is $n^{l}$ and the measure of high-type buyers is $n^{h}$ with $n^{l}+n^{h}=1$. The common discount factor is $\beta$.

While consumption and production goods are non-storable, there is a storable object called money. Money is perfectly divisible and agents can hold any quantity up to the total nominal stock, i.e. $0 \leq m \leq M$. Money (e.g. a simple piece of paper) has no intrinsic value, i.e. so called "fiat money." Since agents are anonymous and there is no double coincidence of wants, agents need money to trade 6

We assume that there is a monetary authority called central bank that prints fiat money at zero cost. The supply of money $M$ changes according to $M_{t}=$ $\mu M_{t-1}$. We assume that the central bank, in the first market, injects money through lump-sum transfers $\tau=(\mu-1) M_{t-1}$. If $\mu<1$, this means that the central bank has the ability to tax agents.

\subsection{Consumption and Production}

Let $p_{1}$ be the price of goods in the first market. We study equilibria where beginning-of-period real money balances are time-invariant:

$$
\frac{M_{t}}{p_{1, t}}=\frac{M_{t-1}}{p_{1, t-1}}
$$

We refer to it as a stationary equilibrium. This lets us omit the time subscript, when understood, and study a representative period, working backwards from the second to the first market - within that period.

\subsubsection{The Last Market}

Let $V_{j}(m)$ denote the value from trading in the second market of period $t$ with $m$ real units of money and type $j \in\{h, l, s\}$. Define $W_{j}(m)$ accordingly for the first market. Let $q$ and $q_{s}$ be the quantities bought by a buyer, respectively sold by a seller, trading in the second market. An agent with $m$ real money balances

\footnotetext{
${ }^{6}$ See also Wallace (2002) for a discussion about anonymity.
} 
and type $j \in\{h, l, s\}$ at the opening of the second market solves the following program

$$
\begin{aligned}
& V_{i}(m)=\max _{0 \leq q \leq m} \varepsilon^{i} u(q)+\beta W_{i}\left[(m-q) \frac{p_{2}}{p_{1,+1}}\right] \quad \forall i \in\{h, l\} \\
& V_{s}(m)=\max _{q_{s} \geq 0}-q_{s}+\beta W_{s}\left[\left(m+q_{s}\right) \frac{p_{2}}{p_{1,+1}}\right]
\end{aligned}
$$

for being buyer or seller, respectively.

Sellers. As a seller, an agent chooses $q_{s}$ to maximize $V_{s}$. The first-order condition is

$$
\beta \frac{p_{2}}{p_{1,+1}} W_{s}^{\prime}\left[\left(m+q_{s}\right) \frac{p_{2}}{p_{1,+1}}\right] \leq 1 \quad\left(=\text { if } q_{s}>0\right)
$$

We can interpret the left-hand side of $(3)$ as the marginal revenue of a trade in the second market and the right-hand side as the marginal cost of producing a good. A seller can acquire money in the first or in the second market and will do so at the lowest cost. Since sellers have the same linear production cost in both markets, they are only indifferent if the prices in both markets are equal, adjusted for discounting. In this case, they are willing to supply all that is demanded, so the supply curve in the second market is flat.

Buyers. As a buyer, an agent chooses $q$ to maximize $V_{i}$ given her cash constraint

$$
q \leq m
$$

and her state $i \in\{h, l\}$

Letting $\lambda_{i} \geq 0$ be the Lagrangian on the cash constraint for all $i \in\{h, l\}$ yields the following first-order conditions:

$$
\begin{aligned}
\varepsilon^{i} u^{\prime}(q)-\beta \frac{p_{2}}{p_{1,+1}} W_{i}^{\prime}\left[(m-q) \frac{p_{2}}{p_{1,+1}}\right]-\lambda_{i} \leq 0 \quad(=0 \text { if } q>0) \\
\lambda_{i}(m-q)=0
\end{aligned}
$$

\subsubsection{The First Market}

Let $x$ and $h$ be the quantities bought, respectively sold, by an agent trading in the first market. There, agents choose how many working units to offer, $h$, how much to buy, $x$, and how much real money to take into the next period, $m^{\prime}$. Hence, an 
agent of type $j$ and real money holdings $m$ at the beginning of the first market solves the following program:

$$
\begin{gathered}
W_{j}(m)=\max _{x, h, m^{\prime}} U(x)-h+V_{j}\left(\frac{p_{1}}{p_{2}} m^{\prime}\right) \\
\text { s.t. } \quad x+m^{\prime}=h+m+\frac{\tau}{p_{1}}
\end{gathered}
$$

where $\tau$ is the nominal lump-sum transfer from the central bank. Note that sellers receive no transfers, i.e. $\tau=0$ in (6) for sellers. Agents only discount future periods, but not sub-periods.

After substituting for $h$, we get the following first-order condition for consumption for all types of agents $j \in\{h, l, s\}$ :

$$
U^{\prime}(x)=1
$$

According to (7), the marginal utility of buying equals the marginal cost of producing a good. Thus, trades are always efficient in the first market.

The first-order condition for the choice of real money holdings $\mathrm{m}^{\prime}$ satisfies

$$
\frac{p_{1}}{p_{2}} V_{j}^{\prime}\left(\frac{p_{1}}{p_{2}} m^{\prime}\right) \leq 1 \quad\left(=1 \text { if } m^{\prime}>0\right)
$$

Equation (8) implies that the amount of money buyers take into the second market depends on their preference parameter $\varepsilon$ which is either high or low. Consequently, the distribution of intermarket money holdings of buyers has two mass points in contrast to the standard model of Lagos and Wright 2005). As shown below, $p_{1} / p_{2}=\beta / \mu$ and for sellers $V_{s}^{\prime}(\cdot)=1$. Therefore, $m^{\prime}=0$ for them if $\beta>\mu$. Intuitively, sellers have no benefit from using money in the second market. Hence, they consume all of their previous earnings and enter the second market without money holdings.

Envelope conditions. The envelope condition for the first market is

$$
W_{j}^{\prime}(m)=1 \quad \forall j \in\{h, l, s\}
$$

Using (3) and (9) we can thus state that

$$
\frac{p_{1,+1}}{p_{2}}=\beta
$$


Then, let us differentiate (2) with respect to $m$ to get the envelope condition for the second market

$$
\begin{aligned}
V_{i}^{\prime}(m) & =\beta \frac{p_{2}}{p_{1,+1}} W_{i}^{\prime}\left[(m-q) \frac{p_{2}}{p_{1,+1}}\right]+\lambda \quad \forall i \in\{h, l\} \\
V_{s}^{\prime}(m) & =\beta \frac{p_{2}}{p_{1,+1}} W_{s}^{\prime}\left[(m+q) \frac{p_{2}}{p_{1,+1}}\right]
\end{aligned}
$$

From (5), 8), and 111a) it further follows that

$$
\varepsilon u^{\prime}(q)=\frac{p_{2}}{p_{1}}
$$

Using (1) and (10) yields

$$
\frac{\mu-\beta}{\beta}=\varepsilon^{i} u^{\prime}\left(q_{i}\right)-1 \quad \forall i \in\{h, l\}
$$

which is the standard equilibrium condition in Lagos and Wright 2005).

Finally, let $q^{*}$ be the solution to $\varepsilon u^{\prime}(q)=1$ and let $m^{*}=q^{*}$. Then, we can state the following:

Lemma 1. In equilibrium, if

(i) $m \geq m^{*}$, then $\lambda=0, q=q^{*}$, and $V_{i}(m)$ is linear

(ii) $m<m^{*}$, then $\lambda>0, q<q^{*}$, and $V_{i}(m)$ is concave

for all buyer types $i \in\{h, l\}$

Lemma 1 shows that trades in the second market are efficient if and only if a buyer of type $i$ holds at least $m_{i}^{*}$ units of money. A proof of this lemma can be found in appendix A.1.

\section{Equilibria}

The key element of our model is that different preference parameters generate a distribution of money holdings in both markets, i.e. every buyer with a high preference parameter $\varepsilon^{h}$ enters the following period with $m_{1}^{h}$ units of real money and those with a low one, $\varepsilon^{l}$, with $m_{1}^{l}$ units.

To determine the equilibria in our model, we first state the following:

Definition 1. A stationary monetary equilibrium is a 
- time-invariant list $\left\{x, h, q_{h}, q_{l}, q_{s}, m_{1}^{h}, m_{1}^{l}\right\}$ and a

- sequence of prices and money holdings $\left\{p_{1}, p_{2}, \lambda_{h}, \lambda_{l}\right\}$

that satisfy (1)-(8).

We can now state our main proposition regarding the existence and uniqueness of monetary equilibria.

Proposition 1. A stationary monetary equilibrium exists if and only if $\mu \geq \beta$. For $\mu=\beta$, we have $q_{l}=q_{l}^{*}<q_{h}=q_{h}^{*}$ and for $\mu>\beta, q_{l}<q_{l}^{*}, q_{h}<q_{h}^{*}$ and $q_{l}<q^{h}$. If $\mu>\beta$, the monetary equilibrium is unique.

The proof of proposition 1 can be found in appendix A.2. It implies that the money growth rate $\mu$ cannot be smaller than $\beta$. With a lower money growth rate, each agent would attempt to accumulate as much money as possible. Analyzing the money holdings, we can state that $m_{2}^{h} \geq m_{2}^{l}$ in any monetary equilibrium. The reason why high-type agents hold more money than low-type agents is that the opportunity cost of holding money is higher for low-type agents since they get less consumption utility.

Note that proposition 1 states that money is neutral, but not superneutral. Increasing its stock has no effect on the quantities consumed, while changing the money growth rate $\mu$ does. Moreover, $\mu=\beta$ generates the first-best allocation in our economy.

\subsection{Inflation Tax}

In the following, we discuss how the inflation tax affects consumption and money holdings. Further, we study how welfare and expected lifetime utilities are affected by marginal changes in the money growth rate.

From 12], it is straightforward that inflation reduces first-period consumption and real money holdings of both types of agents, respectively:

$$
\frac{\partial q_{i}}{\partial \mu}=\frac{1}{\beta \varepsilon^{i} u^{\prime \prime}\left(q_{i}\right)}<0 \quad \forall i \in\{h, l\}
$$

Figure 2 shows that money holdings are decreasing with inflation 7

7For our numerical illustrations, we use a standard CRRA utility function. 


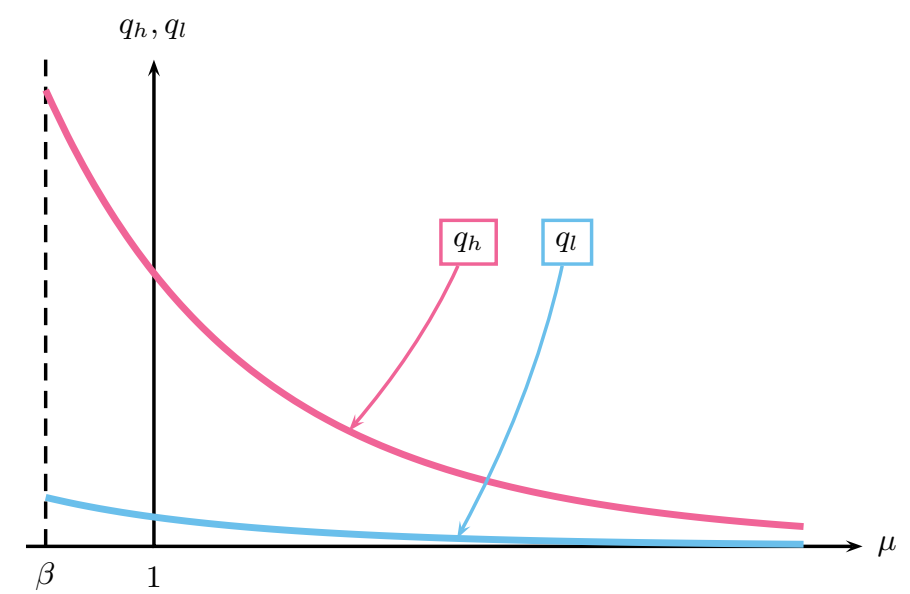

Figure 2: Effect of the inflation tax on buying and selling quantities

From (1) and (6), let us now derive the buyers' expected lifetime utilities in the first market in equilibrium:

$$
W_{i}(m)=U\left(x_{i}^{*}\right)-\left[x_{i}^{*}+m^{\prime}-m-\frac{\tau}{p_{1}}\right]+V_{i}\left(m^{\prime}\right)
$$

Inserting (2) yields

$$
W_{i}(0)=\Psi_{i}-m^{\prime}+\frac{\tau}{p_{1}}+\varepsilon u(q)+\beta W_{i}(0)
$$

where $\Psi_{i} \equiv U\left(x_{i}^{*}\right)-x_{i}^{*}$ is a constant and where $m=0$ since buyers, in equilibrium, enter the first market without cash (see proposition 1 . Solving for the value functions using the fact that $\tau / p_{1}=(\mu-1)\left(n^{h} q_{h}+n^{l} q_{l}\right)$ noting that $m^{\prime}=\mu q$ we get

$$
\begin{aligned}
W_{h}(0) & =\frac{\Psi+\varepsilon^{h} u\left(q_{h}\right)-q_{h}+(\mu-1)\left(q_{l}-q_{h}\right) n^{l}}{1-\beta} \\
W_{l}(0) & =\frac{\Psi+\varepsilon^{l} u\left(q_{l}\right)-q_{l}+(\mu-1)\left(q_{h}-q_{l}\right) n^{h}}{1-\beta}
\end{aligned}
$$

The term $(\mu-1)\left(q_{l}-q_{h}\right) n^{l}$ represents the inflation tax for the high-type agents. If $\mu>1$, inflation redistributes real purchasing power from high- to low-type buyers. In contrast, if $\mu<1$, inflation leads to a real transfer from low to high types.

A numerical illustration of 14 ) is depicted in figure 3. 


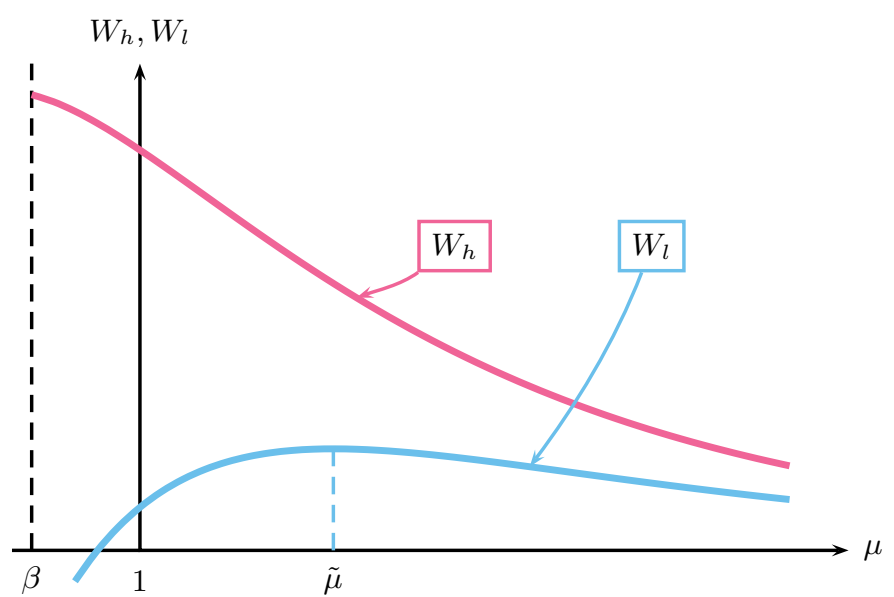

Figure 3: Equilibrium expected utilities of high- and low-type agents

Using this, we can examine how the expected lifetime utilities change with the growth rate of the money supply $\mu$.

$$
\begin{aligned}
& \frac{\partial W_{h}(0)}{\partial \mu}=\frac{\left[\varepsilon^{h} u^{\prime}\left(q_{h}\right)-1\right] \frac{\partial q_{h}}{\partial \mu}+n^{l}\left(q_{l}-q_{h}\right)+(\mu-1) n^{l}\left(\frac{\partial q_{l}}{\partial \mu}-\frac{\partial q_{h}}{\partial \mu}\right)}{1-\beta} \\
& \frac{\partial W_{l}(0)}{\partial \mu}=\frac{\left[\varepsilon^{l} u^{\prime}\left(q_{l}\right)-1\right] \frac{\partial q_{l}}{\partial \mu}+n^{h}\left(q_{h}-q_{l}\right)+(\mu-1) n^{h}\left(\frac{\partial q_{h}}{\partial \mu}-\frac{\partial q_{l}}{\partial \mu}\right)}{1-\beta}
\end{aligned}
$$

Note that $\partial q_{i} / \partial \mu$ is given by 13 . The first term on the right-hand side of 15 is always negative because the marginal utilities are greater or equal to 1 and $\frac{\partial q}{\partial \mu}<0$. This term represents the loss of utility since consumption decreases as the inflation rate increases. This is a standard effect in many models of money.

The second and the third term are derived from $(\mu-1)\left(q_{l}-q_{h}\right) n^{l}$ of 1 14). The second term is the direct effect of the inflation tax. For high-type agents this effect is always negative since in equilibrium $q^{l}<q^{h}$, whereas it is always positive for low-type agents. It describes the change of the transfer of real money from high- to low-type agents. If $\mu>1$, high types transfer money to low types. An increase in inflation then means that the transfer also increases. For $\mu<1$, high types receive transfers from the low types. An increase in the money growth rate reduces that transfer.

Let us now have a look at the third term on the right-hand side of (15). Using 13), we see that the last term of $15 \mathrm{a}$ will be negative if the money growth rate 
is smaller than one and positive for a higher money growth rate. For $15 \mathrm{~b}$ this is just the opposite as it is positive in a deflationary, but negative in an inflationary, environment. This term reflects the indirect effect of a change in $\mu$. A change in $\mu$ affects the quantities, and through this, the amount of money each agent carries. This can be seen from figure 2 where the difference between $q^{h}$ and $q^{l}$ is decreasing in $\mu$. For $\mu>1$, the high-type buyer transfers money to the lowtype buyer and thus benefits from an increase in the money growth rate since the difference between $q^{h}$ and $q^{l}$ and the transfer are decreasing. For $\mu<1$, the high type receives a transfer. In this case, since the difference between $q^{h}$ and $q^{l}$ and the transfer are decreasing, he loses.

\subsection{Monetary Policy}

Friedman (1969) analyzed the effects of inflation in a hypothetical simple society. He found that the optimal policy is to set the nominal interest rate at zero. In the standard representative agent model, from the Fisher equation, $1+i=R(1+\pi)$, where $R$ is the real return on a one-period bond and $\pi$ is the inflation rate, the Friedman Rule implies that the gross growth rate of the money supply is equal to the discount factor of the representative agent. Here, the same logic applies. The real returns in the second market are $R=\frac{1}{\beta}$. We will refer to a policy where $\mu \rightarrow \frac{1}{R}$ as the Friedman Rule.

Because the quantities bought are maximal at $\mu=\beta$, the social planner will always implement the Friedman Rule. In our model with heterogeneous agents, the Friedman Rule is not the only Pareto efficient policy. Let us now state the following proposition.

Proposition 2. For agents with a high marginal utility, the Friedman Rule is the optimal monetary policy. For low-type agents, the optimal money growth rate is strictly greater than the Friedman Rule, but smaller than infinity.

For a formal proof we refer to appendix A.3 In figure 3 , the statement of proposition 2 is shown clearly. We see that the optimal money growth rate for the low-type agents is above the Friedman Rule. This result raises the interesting political economy question of which monetary policy is chosen in equilibrium. We will discuss that in the following section. 


\section{Institutional Arrangements}

We now study various central bank designs. As in Bullard and Waller (2004), we define a central bank design as "a social arrangement for deciding upon a monetary policy" 8 The monetary policy is simply a choice for $\mu \in[\beta, \infty)$.

We assume that at the beginning of each period - before entering the first market - a policy board meeting takes place. There, a representative of the hightype buyers and one of the low-type buyers meet to make a decision on monetary policy, the value of $\mu$. In the following, we let them make their decision depending on various alternative institutional arrangements, i.e. majority voting, supermajority voting, and bargaining. Once the decision on the money growth rate is made, agents start operating in the first market where they get the new transfer from the central bank, $\tau$. Note that we only analyze how buyers decide over the money growth rate. Sellers are not affected by any such decision since they do not consume in the second market and receive no transfers of money in the first market. Figure 4 depicts the timing of the decision making.

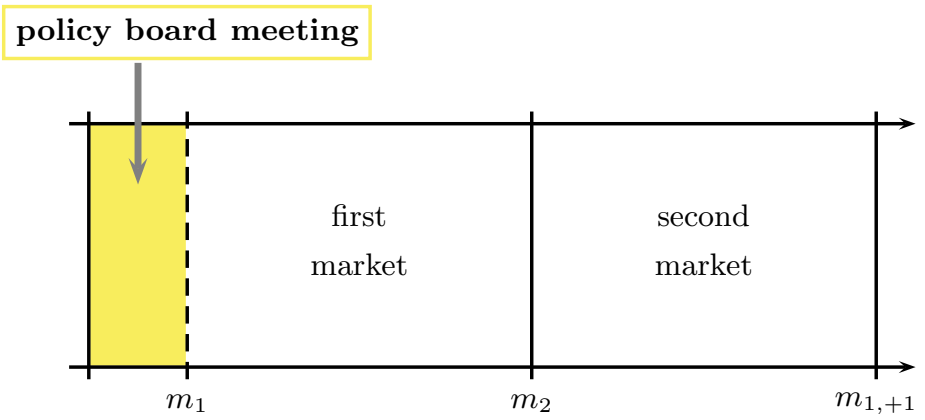

Figure 4: Timing of decisions

The outcome of the policy board depends sometimes on the status quo inflation which is the inflation rate that prevailed during the past period. We denote this status quo inflation as $\bar{\mu}$. Second, in order to point out the influence that the inflation rate has on the value functions of buyers, we will from now on rewrite

\footnotetext{
${ }^{8}$ We do not analyze how society can commit to certain social arrangements. This issue is beyond the scope of our analysis.
} 
them as

$$
W_{i}(\mu) \quad \forall i \in\{h, l\}
$$

In the following, we analyze simple-majority voting, supermajority voting, as well as bargaining with and without transfers. Finally, we compare our results.

\section{I Simple-Majority Voting}

Let us now analyze the outcomes of the most simple institutional arrangement. We assume that the two policy board member's voting weights are according to the population size they represent. Then, the central bank will adjust the transfer $\tau$ in the first market to the new level.

Let $\tilde{\mu}=\arg \max _{\mu} W_{l}(\mu)$. Using proposition 2 , we can then state the following:

Corollary 1. Under simple-majority voting, the unique stationary equilibrium outcome is associated with a money growth rat 9

- $\mu=\beta$, for $n^{h}>n^{l}$.

- $\mu=\tilde{\mu}$, for $n^{l}>n^{h}$.

The results of corollary 1 are intuitive if not to say obvious. Nevertheless, they are in stark contrast to the overlapping generations model of Bullard and Waller (2004) which yields hyperinflation as the outcome of simple-majority voting if the young generation has a majority. We never obtain hyperinflation since it is never optimal for any buyer type.

\subsection{Supermajority Voting}

In the supermajority (or qualified majority) voting case, the minority has a veto power. This means that the majority needs to offer a money growth rate that makes the minority not worse off than at the status quo money growth rate $\bar{\mu}$. This is similar to a take-it-or-leave-it offer problem. The difference is that the majority may want an inflation rate that is also better for the other type. We

${ }^{9}$ We do not analyze the case where $n^{l}=n^{h}$. 
will, however, see that in our model supermajority voting reduces to a take-itor-leave-it offer problem. We assume that the majority proposes the following new money growth rate to the minority:

$$
\begin{aligned}
& \mu=\arg \max _{\mu \geq \beta} W_{i}(\mu) \\
& \text { s.t. } \quad W_{-i}(\mu) \geq W_{-i}(\bar{\mu})
\end{aligned}
$$

where $i$ represents the majority type and $-i$ the minority.

Let $\hat{\mu}$ be the solution to $W_{l}(\mu)=W_{l}(\bar{\mu})$ with $\hat{\mu} \leq \bar{\mu}$. The outcome to supermajority voting is then presented in the following:

Corollary 2. Under supermajority voting, if $\bar{\mu}>\tilde{\mu}$ then $\mu=\hat{\mu}$, for $n^{h}>n^{l}$, and if $\mu=\tilde{\mu}$, for $n^{l}>n^{h}$. If $\bar{\mu} \leq \tilde{\mu}$, then $\mu=\bar{\mu}$.

For a proof, see the proof of corollary 3 in appendix A.4 If $\bar{\mu} \leq \tilde{\mu}$, both types of agents have diverging wants and so the outcome is the status quo money growth rate.

If $\bar{\mu}>\tilde{\mu}$, we need to know who has the majority. Consider the high-type agents. They want the Friedman Rule. The best they can do, however, is to make the low-type agents indifferent by reducing the inflation rate to $\mu=\hat{\mu}$. Now, consider the case where the low-type agents have the majority. They want $\mu=\tilde{\mu}$. In contrast to the high types they can attain this since the reduction from $\bar{\mu}$ to $\tilde{\mu}$ benefits both types. Figure 5 shows the supermajority outcomes for both highand low-type majorities in our numerical examples, respectively.

\subsection{Bargaining}

Now, let us consider the case where the two representatives bargain over the money growth rate $\mu$. In order to do this, we analyze the asymmetric Nash bargaining solution.

\subsubsection{Bargaining without Transfers}

In this case, buyers bargain over $\mu$ without being able to compensate each other using lump sum transfers. Thus, we have

$$
\begin{gathered}
\mu=\arg \max _{\mu}\left[W_{h}(\mu)-W_{h}(\bar{\mu})\right]^{\theta}\left[W_{l}(\mu)-W_{l}(\bar{\mu})\right]^{1-\theta} \\
\text { s.t. } \quad \mu \geq \beta
\end{gathered}
$$




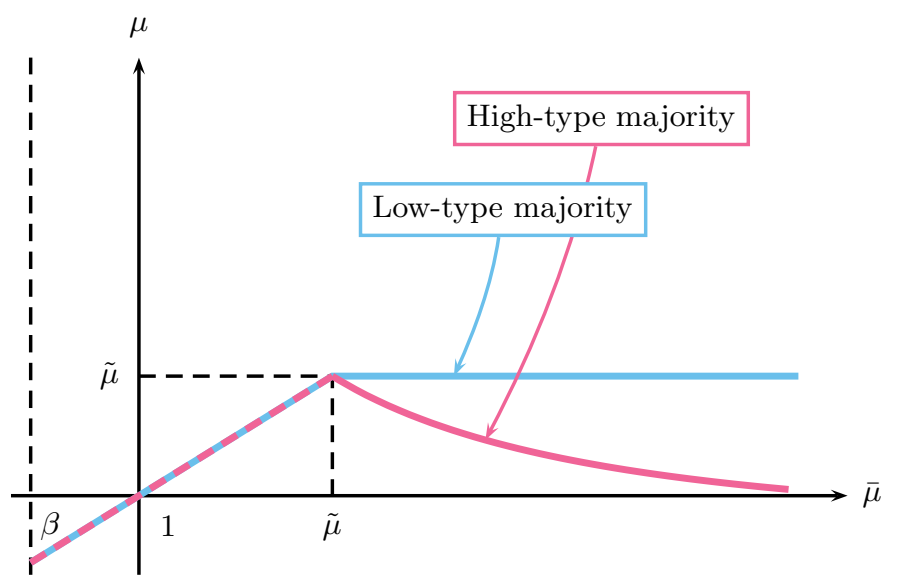

Figure 5: Supermajority outcome for a majority of high- and low-type buyers

where the threat-points are the value of each agent at the status quo money growth rate $\bar{\mu}$. The first-order conditions are

$$
\begin{gathered}
\theta \frac{\partial W_{h}(\mu)}{\partial \mu}\left[W_{l}(\mu)-W_{l}(\bar{\mu})\right]+(1-\theta) \frac{\partial W_{l}(\mu)}{\partial \mu}\left[W_{h}(\mu)-W_{h}(\bar{\mu})\right]+\lambda=0 \\
\lambda(\mu-\beta)=0
\end{gathered}
$$

where $\lambda$ is the Lagrange multiplier.

For any status quo money growth rate $\bar{\mu} \geq \beta$, we can derive the resulting bargaining solution. Figure 6 displays all possible solutions for the same parameters that we used for figure 3 .

This leads to the following:

Corollary 3. If $\theta=1$, the outcome of the Nash bargaining solution without transfers coincides with the supermajority voting outcome if $n^{h}>n^{l}$. If $\theta=0$, the outcome coincides with the supermajority voting outcome if $n^{l}>n^{h}$. For $\theta \in(0,1)$, the resulting inflation rate lies in between the two previous cases.

For a proof, we refer to appendix A.4 The inflation rate with bargaining without transfers lies in between the cases of supermajority voting. The intuition is that supermajority voting are basically take-it-or-leave-it offers.

Note that the asymmetric Nash bargaining solution always yields to a Pareto optimal solution. Because of this, if the status quo inflation rate is not Pareto 


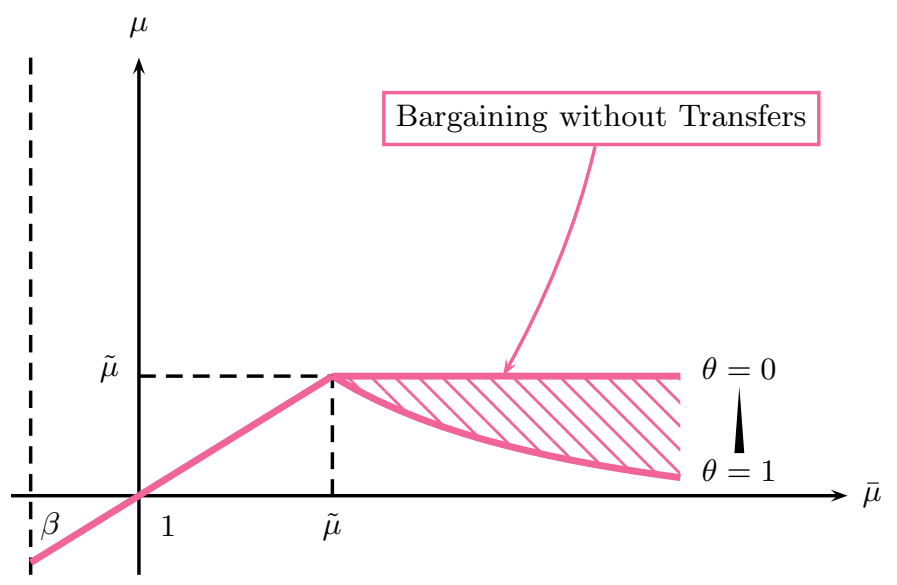

Figure 6: Nash bargaining solution (y-axis) as a function of the status quo money growth rate (x-axis).

efficient, there will be a one-time jump to a Pareto efficient inflation rate after which no further changes occur.

\subsubsection{Bargaining with Transfers}

Let us now analyze the bargaining problem when the two parties have the ability to compensate each other with transfers. Transfers have to be regarded as a kind of subsidy from the one type of agent to the other. With transfers, the policy board bargains over the money growth rate $\mu$ and a transfer $z$ taking into account that $\mu \geq \beta$. This case is interesting for two reasons. First, it yields a benchmark to which we can compare our other outcomes. Second, the policy board can agree on outcomes which, in the absence of transfers, would not satisfy the participation constraint of one of the two groups.

The bargaining power of the high-type agent is again $\theta$, so we have the following bargaining solution:

$$
\begin{gathered}
\mu=\arg \max _{\mu, z}\left[W_{h}(\mu)-z-W_{h}(\bar{\mu})\right]^{\theta}\left[W_{l}(\mu)+z-W_{l}(\bar{\mu})\right]^{1-\theta} \\
\text { s.t. } \quad \mu \geq \beta
\end{gathered}
$$


The first-order conditions then are

$$
\begin{array}{r}
\theta \frac{\partial W_{h}(\mu)}{\partial \mu}\left[W_{l}(\mu)-z-W_{l}(\bar{\mu})\right] \\
+(1-\theta) \frac{\partial W_{l}(\mu)}{\partial \mu}\left[W_{h}(\mu)+z-W_{h}(\bar{\mu})\right]+\lambda=0 \\
-\theta\left[W_{l}(\mu)-z-W_{l}(\bar{\mu})\right]+(1-\theta)\left[W_{h}(\mu)+z-W_{h}(\bar{\mu})\right]=0 \\
\lambda(\beta-\mu)=0
\end{array}
$$

where $\lambda$ is the Lagrange multiplier.

Rearranging, we get for the first one the following condition

$$
\frac{\partial W_{h}(\mu)}{\partial \mu}+\frac{\partial W_{l}(\mu)}{\partial \mu}+\hat{\lambda}=0
$$

where $\hat{\lambda}=\lambda /\left\{(1-\theta)\left[W_{h}(\mu)+z-W_{h}(\bar{\mu})\right]\right\}$. This leads to the following

Corollary 4. Nash bargaining over the money growth rate with lump-sum transfers leads to the Friedman Rule.

The proof is in appendix A.5. As we have expected, the outcome is the Friedman rule which is the optimal policy from a high type's point of view. This result provides an interesting link between monetary policy and fiscal policy, which is absent in all other models that consider optimal central bank design. It states that when different groups in society have different inflation goals, the best monetary policy can nevertheless be implemented. It requires, however, that fiscal and monetary policy are jointly determined. That is, the policy board implements the Friedman rule and at the same time fiscal policy is used to compensate the party that loses from this monetary arrangement.

\subsection{Comparison}

Let us finally compare our results to the socially optimal case. We have shown in proposition 1 that the Friedman-Rule, $\mu=\beta$, generates the first-best allocation in our economy and is thus the policy that a social planner would choose. However, we have just seen that many central bank designs do not achieve the social optimum, especially when low-type buyers are in the majority. Hence, which central bank design is best at achieving the social optimum? 
We can now answer this question. First, note that there is a candidate who will always achieve the social optimum: bargaining with transfers. This mechanism is closely related to a fiscal policy scheme by using compensations in order to achieve monetary policy goals. However, it is hard to implement such a scheme in reality as it involves not only the central bank, but also the governments, not to mention the asymmetric information problems likely to appear. Let us thus focus on the other designs discussed.

If there is a majority of inflation-averse agents, i.e. high-type agents, the only institutional arrangement to achieve the social optimum will be a simple-majority voting mechanism. Then, high-type buyers would vote (and win) for the Friedman Rule. No other central bank design (apart from the one discussed above) achieves this.

In the case of a minority of inflation-averse agents, the Friedman Rule is only achieved through bargaining with transfers. Moreover, implementing simplemajority voting would lead to the highest money growth rate possible with any institutional arrangement, $\tilde{\mu}$. Furthermore, a supermajority voting rule will either implement the status quo money growth rate, if it is low, or implement the highest possible money growth rate possible. This is in stark contrast to the findings of Bullard and Waller 2004) who show that in an oLg model supermajority leads to the social optimum by forcing the young agents (less inflation-averse, like the low-type agents in our model) "to choose a monetary policy based on lifetime utility, and thus to create a stationary equilibrium at the social optimum" (p. 112). Thus, the central bank design to come closest to the social optimum in our model will be the bargaining case with bargaining power as large as possible for the inflation-averse agents. In other words, if the policy board gives inflationaverse agents more power to less inflation-averse participants, relatively, the outcome will be the closest to the social optimum possible. This result is related to the findings of Fatum (2006 - albeit derived in a very different framework - who shows that a "weighted mean mechanism" leads to a heavier weight for inflation-averse agents and thus to a policy of lower inflation rates. 


\section{Extension}

Erosa and Ventura (2002) studied the distributional impact of inflation in a monetary growth model. They found, that inflation has "important distributional effects since it is effectively a regressive consumption tax". They show that wealthy agents are less affected by the inflation tax than poor agents. The reason is that wealthy agents have access to financial markets which allows them to avoid the inflation tax. We can easily accommodate our model to take into account of their findings as follows. We can interpret the first market as the place where consumption occurs without money. Let us redefine the utility in the first market to be $\epsilon^{i} U(x)$ for all $i \in\{h, l\}$ and assume $\epsilon^{l}>\epsilon^{h}$. The first-order conditions are $\epsilon^{i} U^{\prime}\left(x_{i}^{*}\right)=1$ with $x_{l}^{*}>x_{h}^{*}$. We can choose $\epsilon^{h}$ and $\epsilon^{l}$ such that the value of total consumption in both markets of the low types is strictly higher than the one of the high types. Moreover, with this arrangements, the fraction of consumption in market 1 to total consumption is strictly higher for high types. With this change, the model is in accordance with the empirical findings of Erosa and Ventura (2002) that poor people suffer more from the inflation tax than rich people.

\section{Conclusion}

We consider a micro-founded model of money where monetary policy has redistributive effects. In this framework we analyze the outcome of various central bank designs. We find that the only central bank design that consistently yields the first-best allocation is Nash bargaining with transfers. This result provides an interesting link between monetary policy and fiscal policy. It states that when different groups in society have different inflation goals, the best monetary policy can nevertheless be implemented. It requires, however, that fiscal and monetary policy are jointly determined. That is, the policy board implements the first-best inflation rate and at the same time fiscal policy is used to compensate the party that loses from this new monetary arrangement.

However, this finding requires some caution. In our analysis we have completely abstracted from asymmetric information problems and public choice issues. Incorporating such considerations into the analysis may change our results. These 
are interesting questions for future research. 


\section{A Appendix}

\section{A.1 Proof of Lemma 1}

Constraint is not binding. If $\lambda_{i}=0$, from (5), (9), and (10), we have for all types of buyers

$$
\varepsilon^{i} u^{\prime}(q)=1 \quad \Rightarrow q=q^{*}
$$

The amount of money agents spend is $q^{*}=m^{*}$. To examine linearity of $V$, note that from (9), 10, and 11a) we have

$$
V_{i}^{\prime}(m)=1 \quad \forall i \in\{h, l\}
$$

Constraint is binding. If $\lambda_{i}>0$, from (5), (9), and (10), we have

$$
\varepsilon^{i} u^{\prime}(q) \leq 1+\lambda_{i} \quad \text { and } \quad m=q
$$

Hence, trades are always inefficient. To examine the shape of $V$, note that from (5), (9), 10), and (11a) we have

$$
\frac{\partial V_{i}(m)}{\partial m}=\left[\varepsilon^{i} u^{\prime}(q)-1\right]+1
$$

We see that $V_{i}(m)$ is concave for all $m<m^{*}$ since $u(q)$ is concave by assumption for all buyers' types $i \in\{h, l\}$.

\section{A.2 Proof of Proposition 1}

Constraints are not binding. In this case $q^{h}=q_{h}^{*}>q^{l}=q_{l}^{*}$. From (9), 10, and (11a) we have

$$
V_{i}^{\prime}(m)=1 \quad \forall i \in\{l, h\}
$$

These conditions state that if agents take a unit of money into the second market, but do not intend to spend it in this market (because they still have enough money), then the value of this extra unit of money is the goods it buys in the subsequent first market. Substituting these equations into the first-order conditions for the choice of money holdings (8)

$$
p_{1}=p_{2} \quad \Rightarrow \quad \frac{p_{1}}{p_{1,+1}}=\frac{p_{2}}{p_{1,+1}}
$$


In a steady state equilibrium, $\frac{M}{p_{2}}=\frac{M_{-1}}{p_{2,-1}}$, implying $\frac{p_{2}}{p_{2,-1}}=\mu$. Using this fact together with 10 yields

$$
\mu=\beta
$$

Thus for $\mu=\beta$, no agent is cash-constrained and we have a monetary equilibrium with $q^{h}=q^{*}\left(\varepsilon^{h}\right)>q^{l}=q^{*}\left(\varepsilon^{l}\right)$.

Constraints are binding. In this case $q^{h}<q_{h^{\prime}}^{*} q^{l}<q_{l}^{*}$, and $q^{h}>q^{l}$. From 12 we have already derived the following equilibrium condition:

$$
\frac{\mu-\beta}{\beta}=\varepsilon^{i} u^{\prime}\left(q_{i}\right)-1 \quad \forall i \in\{h, l\}
$$

Equation (24) yields unique values for $q$. The equilibrium money holdings $m$ and the price level $p_{1}$ can be derived by solving the following three equations:

$$
\begin{aligned}
q^{i} & =m^{i} \quad \forall i \in\{l, h\} \\
n^{h} m^{h}+n^{l} m^{l} & =\frac{M}{p_{2}}
\end{aligned}
$$

Thus, if $\mu>\beta$, a unique monetary equilibrium exists.

\section{A.3 Proof of Proposition 2}

High-type agents. Let us start with the first claim of proposition 2 The hightype buyers prefer the Friedman Rule if, from (15a) and (13),

$$
\frac{\varepsilon^{h} u^{\prime}\left(q_{h}\right)-1}{\beta \varepsilon^{h} u^{\prime \prime}\left(q_{h}\right)}+n^{l}\left(q_{l}-q_{h}\right)+(\mu-1) n^{l}\left(\frac{1}{\beta \varepsilon^{l} u^{\prime \prime}\left(q_{l}\right)}-\frac{1}{\beta \varepsilon^{h} u^{\prime \prime}\left(q_{h}\right)}\right)<0
$$

Since the first and second term are negative, a sufficient condition for this derivative to be negative is $\mu \leq 1$ and

$$
\varepsilon^{l} u^{\prime \prime}\left(q_{l}\right) \leq \varepsilon^{h} u^{\prime \prime}\left(q_{h}\right)
$$

As $\varepsilon^{l} \leq \varepsilon^{h}$, a sufficient condition is that $u^{\prime \prime}\left(q^{l}\right) \leq u^{\prime \prime}\left(q^{h}\right)$ which is true as we have assumed $u^{\prime \prime \prime}(q)>0$. The CRRA utility function $u(q)=q^{1-\gamma} /(1-\gamma)$, for example, satisfies this requirement. Hence, for $\beta \leq \mu \leq 1$, the Friedman Rule is the value maximizing policy for the high-type buyers. To show the same for $\mu>1$ we use the equilibrium condition $(12)$ and rearrange $(25)$ to get

$$
\frac{(\mu-1)}{\beta \varepsilon^{h} u^{\prime \prime}\left(q_{h}\right)}\left\{1+n^{l}\left[\frac{\varepsilon^{h}}{\varepsilon^{l}} \frac{u^{\prime \prime}\left(q_{h}\right)}{u^{\prime \prime}\left(q_{l}\right)}-1\right]\right\}+\frac{(1-\beta)}{\beta \varepsilon^{h} u^{\prime \prime}\left(q_{h}\right)}+n^{l}\left(q_{l}-q_{h}\right)<0
$$


because

$$
1-n^{l}+n^{l} \frac{\varepsilon^{h}}{\varepsilon^{l}} \frac{u^{\prime \prime}\left(q_{h}\right)}{u^{\prime \prime}\left(q_{l}\right)}>0
$$

This proves that high-type buyers maximize their value for each period at the Friedman Rule, $\mu=\beta$.

Low-type buyer. The low-type agents prefer a deviation if their marginal value is positive at the Friedman Rule. From $15 \mathrm{~b}$ and 13 if

$$
\frac{\varepsilon^{l} u^{\prime}\left(q_{l}\right)-1}{\beta \varepsilon^{l} u^{\prime \prime}\left(q_{l}\right)}+n^{h}\left(q_{h}-q_{l}\right)+(\beta-1) n^{h}\left(\frac{1}{\beta \varepsilon^{h} u^{\prime \prime}\left(q_{h}\right)}-\frac{1}{\beta \varepsilon^{l} u^{\prime \prime}\left(q_{l}\right)}\right)>0
$$

At the Friedman Rule, from (12), $\varepsilon^{l} u^{\prime}\left(q^{l}\right)-1=0$. So, the first term is zero. Rearranging the above equation then yields:

$$
n^{h}\left(q_{h}-q_{l}\right)+(\beta-1) n^{h}\left(\frac{1}{\beta \varepsilon_{h} u^{\prime \prime}\left(q_{h}\right)}-\frac{1}{\beta \varepsilon_{l} u^{\prime \prime}\left(q_{l}\right)}\right)>0
$$

Since the first term is positive, a sufficient condition for this derivative to be positive is

$$
\varepsilon^{l} u^{\prime \prime}\left(q^{l}\right) \leq \varepsilon^{h} u^{\prime \prime}\left(q^{h}\right)
$$

which is true.

Let us now show that - in the limit - inflation has a negative impact on the low-type buyers. Note that from (12) we know that

$$
\lim _{\mu \rightarrow \infty} q_{i}=0 \quad \forall i \in\{h, l\}
$$

Hence it follows that

$$
\lim _{\mu \rightarrow \infty} \frac{\varepsilon^{l} u^{\prime}\left(q_{l}\right)-1}{\beta \varepsilon^{l} u^{\prime \prime}\left(q_{l}\right)}+n^{h}\left(q_{h}-q_{l}\right)+(\mu-1) n^{h}\left(\frac{1}{\beta \varepsilon^{h} u^{\prime \prime}\left(q_{h}\right)}-\frac{1}{\beta \varepsilon^{l} u^{\prime \prime}\left(q_{l}\right)}\right)<0
$$

Thus, we have shown that the value maximizing $\mu$ for a low-type buyer is higher than the Friedman Rule, but lower than infinity. Using the result from lemma 1 the value of $\mu$ that maximizes the value of the low type is unique.

\section{A.4 Proof of Corollary 3}

The first-order conditions are

$$
\begin{gathered}
\theta \frac{\partial W_{h}(\mu)}{\partial \mu}\left[W_{l}(\mu)-W_{l}(\bar{\mu})\right]+(1-\theta) \frac{\partial W_{l}(\mu)}{\partial \mu}\left[W_{h}(\mu)-W_{h}(\bar{\mu})\right]+\lambda=0 \\
\lambda(\beta-\mu)=0
\end{gathered}
$$


Using (14) and (15) we get

$$
\begin{aligned}
& \theta\left\{\left[\varepsilon^{h} u^{\prime}\left(q_{h}\right)-1\right] \frac{\partial q_{h}}{\partial \mu}+n^{l}\left(q_{l}-q_{h}\right)+(\mu-1) n^{l}\left(\frac{\partial q_{l}}{\partial \mu}-\frac{\partial q_{h}}{\partial \mu}\right)\right\} \\
& \cdot\left\{\varepsilon^{l} u\left(q_{l}\right)-q_{l}+(\mu-1)\left(q_{h}-q_{l}\right) n^{h}-\varepsilon^{l} u\left(\bar{q}_{l}\right)+\bar{q}_{l}-(\bar{\mu}-1)\left(\bar{q}_{h}-\bar{q}_{l}\right) n^{h}\right\} \\
& +(1-\theta)\left\{\left[\varepsilon^{l} u^{\prime}\left(q_{l}\right)-1\right] \frac{\partial q_{l}}{\partial \mu}+n^{h}\left(q_{h}-q_{l}\right)+(\mu-1) n^{h}\left(\frac{\partial q_{h}}{\partial \mu}-\frac{\partial q_{l}}{\partial \mu}\right)\right\} \\
& \cdot\left\{\varepsilon^{h} u\left(q_{h}\right)-q_{h}+(\mu-1)\left(q_{l}-q_{h}\right) n^{l}-\varepsilon^{h} u\left(\bar{q}_{h}\right)+\bar{q}_{h}-(\bar{\mu}-1)\left(\bar{q}_{l}-\bar{q}_{h}\right) n^{l}\right\} \\
& +\lambda(1-\beta)^{2}=0
\end{aligned}
$$

Simpliying using (13) yields

$$
\begin{gathered}
\theta\left\{\frac{\varepsilon^{h} u^{\prime}\left(q_{h}\right)-1}{\beta \varepsilon^{h} u^{\prime \prime}\left(q_{h}\right)}+n^{l}\left(q_{l}-q_{h}\right)+(\mu-1) n^{l}\left(\frac{1}{\beta \varepsilon^{l} u^{\prime \prime}\left(q_{l}\right)}-\frac{1}{\beta \varepsilon^{h} u^{\prime \prime}\left(q_{h}\right)}\right)\right\} \\
\cdot\left\{\varepsilon^{l} u\left(q_{l}\right)-q_{l}+(\mu-1)\left(q_{h}-q_{l}\right) n^{h}-\varepsilon^{l} u\left(\bar{q}_{l}\right)+\bar{q}_{l}-(\bar{\mu}-1)\left(\bar{q}_{h}-\bar{q}_{l}\right) n^{h}\right\} \\
+(1-\theta)\left\{\frac{\varepsilon^{l} u^{\prime}\left(q_{l}\right)-1}{\beta \varepsilon^{l} u^{\prime \prime}\left(q_{l}\right)}+n^{h}\left(q_{h}-q_{l}\right)+(\mu-1) n^{h}\left(\frac{1}{\beta \varepsilon^{h} u^{\prime \prime}\left(q_{h}\right)}-\frac{1}{\beta \varepsilon^{l} u^{\prime \prime}\left(q_{l}\right)}\right)\right\} \\
\cdot\left\{\varepsilon^{h} u\left(q_{h}\right)-q_{h}+(\mu-1)\left(q_{l}-q_{h}\right) n^{l}-\varepsilon^{h} u\left(\bar{q}_{h}\right)+\bar{q}_{h}-(\bar{\mu}-1)\left(\bar{q}_{l}-\bar{q}_{h}\right) n^{l}\right\} \\
+\lambda(1-\beta)^{2}=0 \quad
\end{gathered}
$$

For the proof of the corollary, we need to split up the above condition into two parts. First, we analyze the case of full bargaining power for the high-type agent. Second, we examine the case where low-type agents have full bargaining power.

If high-type agents have all the bargaining power, condition 27 reduces to

$$
\begin{gathered}
\left\{\frac{\varepsilon^{h} u^{\prime}\left(q_{h}\right)-1}{\beta \varepsilon^{h} u^{\prime \prime}\left(q_{h}\right)}+n^{l}\left(q_{l}-q_{h}\right)+(\mu-1) n^{l}\left(\frac{1}{\beta \varepsilon^{l} u^{\prime \prime}\left(q_{l}\right)}-\frac{1}{\beta \varepsilon^{h} u^{\prime \prime}\left(q_{h}\right)}\right)\right\} \\
\cdot\left\{\varepsilon^{l} u\left(q_{l}\right)-q_{l}+(\mu-1)\left(q_{h}-q_{l}\right) n^{h}-\varepsilon^{l} u\left(\bar{q}_{l}\right)+\bar{q}_{l}-(\bar{\mu}-1)\left(\bar{q}_{h}-\bar{q}_{l}\right) n^{h}\right\} \\
+\lambda(1-\beta)^{2}=0
\end{gathered}
$$

If we are away from the Friedman Rule, the Lagrange multiplier becomes zero, i.e. $\lambda=0$. The bargaining solution in this case is the money growth rate that lets either the first or the second term become zero. From proposition 2 , we know that the first term of $(28)$ is equal to zero only at the Friedman Rule. Hence, the only solution to our problem is to have the last term equal to zero. First, note that from proposition 2 we know that $\mu>\tilde{\mu}$ can never be an optimal money growth 
rate. Hence, for $\bar{\mu} \leq \tilde{\mu}$ only $\mu=\bar{\mu}$ can be a solution to the bargaining problem. Further, for $\bar{\mu}>\tilde{\mu}$, the solution is the money growth rate that gives the same value to the low-type as $\bar{\mu}$.

In the case of full bargaining power for the low-type agents, $\theta=0$, condition 27) reduces to

$$
\begin{aligned}
& \left\{\frac{\varepsilon^{l} u^{\prime}\left(q_{l}\right)-1}{\beta \varepsilon^{l} u^{\prime \prime}\left(q_{l}\right)}+n^{h}\left(q_{h}-q_{l}\right)+(\mu-1) n^{h}\left(\frac{1}{\beta \varepsilon^{h} u^{\prime \prime}\left(q_{h}\right)}-\frac{1}{\beta \varepsilon^{l} u^{\prime \prime}\left(q_{l}\right)}\right)\right\} \\
& \cdot\left\{\varepsilon^{h} u\left(q_{h}\right)-q_{h}+(\mu-1)\left(q_{l}-q_{h}\right) n^{l}-\varepsilon^{h} u\left(\bar{q}_{h}\right)+\bar{q}_{h}-(\bar{\mu}-1)\left(\bar{q}_{l}-\bar{q}_{h}\right) n^{l}\right\} \\
& +\lambda(1-\beta)^{2}=0
\end{aligned}
$$

If we are away from the Friedman Rule, the Lagrange multiplier becomes zero, i.e. $\lambda=0$. Hence, the bargaining solution $\mu$ will be the money growth rate that makes either the first or the second term zero. We know from proposition 2 that $\tilde{\mu}$ is the unique value maximizing money growth rate for low-type agents. Hence, $\mu=\tilde{\mu}$ will always fulfill the above condition. Second, setting $\mu=\bar{\mu}$ will reduce the difference in values for high-type buyers to zero and thus also fulfill the condition. Note that setting $\mu=\bar{\mu}$ for all $\bar{\mu}>\tilde{\mu}$ will minimize 29, as marginal effects are negative for both terms. In other words, lowering the money growth rate would not only increase the value of the low-type agents (the first term), but also increase the difference between the values for the bargaining solution and the status quo money growth rate for the high-type agents (second term). For $\bar{\mu}<\tilde{\mu}$, the bargaining solution must be $\mu=\bar{\mu}$, as the other possible solution, $\mu=\tilde{\mu}$, would again minimize our problem, and not maximize it. The reason is that high-type agents would lose value, whereas low-types would gain. Thus the only Pareto optimal solution is $\mu=\bar{\mu}$.

We have now proved with the use of proposition 2 that the solution of a bargaining without transfers between high- and low-type buyers leads to a money growth rate equal to or in between the supermajority voting outcome. 


\section{A.5 Proof of Corollary 4}

The proof is by contradiction. Assume that we are not at the Friedman rule. Hence, $\lambda=0$, and we get

$$
\begin{aligned}
0 \stackrel{?}{=} & \frac{\partial W_{h}(\mu)}{\partial \mu}+\frac{\partial W_{l}(\mu)}{\partial \mu} \\
\stackrel{?}{=} & \left\{\frac{\varepsilon^{l} u^{\prime}\left(q^{l}\right)-1}{\beta \varepsilon^{l} u^{\prime \prime}\left(q^{l}\right)}+n^{h}\left(q^{h}-q^{l}\right)+(\mu-1) n^{h}\left(\frac{1}{\beta \varepsilon^{h} u^{\prime \prime}\left(q^{h}\right)}-\frac{1}{\beta \varepsilon^{l} u^{\prime \prime}\left(q^{l}\right)}\right)\right\} \\
& +\left\{\frac{\varepsilon^{h} u^{\prime}\left(q^{h}\right)-1}{\beta \varepsilon^{h} u^{\prime \prime}\left(q^{h}\right)}+n^{l}\left(q^{l}-q^{h}\right)+(\mu-1) n^{l}\left(\frac{1}{\beta \varepsilon^{l} u^{\prime \prime}\left(q^{l}\right)}-\frac{1}{\beta \varepsilon^{h} u^{\prime \prime}\left(q^{h}\right)}\right)\right\}
\end{aligned}
$$

where we use our results from the proof of proposition 2

Note that the two above parentheses can only be zero at the same time, when $q^{l}=q^{h}$ which is not possible and thus proves corollary 4 which states that the Friedman Rule is the resulting money growth rate from bargaining with transfers. 


\section{References}

Berentsen, A., G. Camera, and C. J. Waller (2005): "The Distribution of Money Balances and the Nonneutrality of Money," International Economic Review, $46(2), 465-487$.

Bhattacharya, J., J. H. Haslag, and A. Martin (2005): “Heterogeneity, Redistribution, and the Friedman Rule," International Economic Review, 46, 437-454.

Bhattacharya, J., J. H. Haslag, and S. Russell (2005): "The Role of Money in Two Alternative Models: When is the Friedman Rule Optimal, and Why?," Journal of Monetary Economics, 52(8), 1401-1433.

Boel, P., and G. Camera (2006): "Efficient monetary allocations and the illiquidity of bonds," Journal of Monetary Economics, 53, 1693-1715.

Bullard, J., and C. J. Waller (2004): “Central Bank Design in General Equilibrium," Journal of Money, Credit and Banking, 36(1), 95-113.

Erosa, A., and G. Ventura (2002): “On inflation as a regressive consumption tax," Journal of Monetary Economics, 49, 761-795.

Fatum, R. (2006): “One monetary policy and 18 central bankers: The European monetary policy as a game of strategic delegation," Journal of Monetary Economics, 53, 659-669.

Friedman, M. (1969): The Optimum Quantity of Money. Macmillan, London.

Gerling, K., H. P. Grüner, A. KIel, and E. Schulte (2003): “Information Acquisition and Decision Making Committees: A Survey," ECB Working Paper Series, 256.

Hagen, J. v., and R. Süppel (1994): “Central bank constitutions for federal monetary unions," European Economic Review, 38, 774-782.

Haslag, J. H., and A. Martin (2007): “Optimality of the Friedman Rule in Overlapping Generations Model with Spatial Separation," Journal of Money, Credit and Banking, forthcoming. 
Lagos, R., ANd R. Wright (2005): “Monetary Theory and Policy Analysis," Journal of Political Economy, 113(3), 463-484.

Molico, M. (2006): "The Distribution of Money and Prices in Search Equilibrium," International Economic Review, 47(3), 701-722.

Persson, T., and G. Tabellini (2000): Political Economics: Explaining Economic Policy. MIT Press, Cambridge, Massachusetts.

Rocheteau, G., and R. Wright (2005): “Money in Search Equilibrium, in Competitive Equilibrium, and in Competitive Search Equilibrium," Econometrica, 73(1), 175-202.

Wallace, N. (2002): "General Features of Monetary Models and their Significance," Working paper, sNB-Fed Cleveland Workshop on Monetary Policy. 